This is the final peer-reviewed accepted manuscript of

Dedeine, F.; Dupont, S.; Guyot, S.; Matsuura, K.; Habibpour B.; Wang C.; Bagnères, A. G.; MANTOVANI, BARBARA; LUCHETTI, ANDREA: Historical biogeography of Reticulitermes termites (Isoptera:

Rhinotermitidae) inferred from analyses of mitochondrial and nuclear loci. MOLECULAR PHYLOGENETICS

AND EVOLUTION 94. ISSN 11585/537955

DOI: 10.1016/j.ympev.2015.10.020

The final published version is available online at:

http://dx.doi.org/10.1016/i.ympev.2015.10.020

Rights / License: The terms and conditions for the reuse of this version of the manuscript are specified in the publishing policy. For all terms of use and more information see the publisher's website. 


\title{
Historical biogeography of Reticulitermes termites (Isoptera: Rhinotermitidae) inferred from analyses of mitochondrial and nuclear loci ${ }^{\text {负 }}$
}

\author{
Franck Dedeine ${ }^{\mathrm{a}, *, 1}$, Simon Dupont ${ }^{\mathrm{a}, 1}$, Sylvain Guyot ${ }^{\mathrm{a}}$, Kenji Matsuura ${ }^{\mathrm{b}}$, Changlu Wang ${ }^{\mathrm{c}}$, \\ Behzad Habibpour $^{\mathrm{d}}$, Anne-Geneviève Bagnères ${ }^{\mathrm{a}}$, Barbara Mantovani ${ }^{\mathrm{e}}$, Andrea Luchetti ${ }^{\mathrm{e}}$ \\ a Institut de Recherche sur la Biologie de l'Insecte, UMR 7261, Université François Rabelais de Tours, Parc Grandmont, 37200 Tours, France \\ ${ }^{\mathrm{b}}$ Laboratory of Insect Ecology, Graduate School of Agriculture, Kyoto University, Oiwakecho, Kitashirakawa, Sakyo-ku, Kyoto 606-8502, Japan \\ ${ }^{\mathrm{c}}$ Department of Entomology, Rutgers University, New Brunswick, NJ 08901, USA \\ ${ }^{\mathrm{d}}$ Department of Plant Protection, College of Agriculture, University of Shahid-Chamran, Ahwaz, Iran \\ e Dipartimento di Scienze Biologiche, Geologiche e Ambientali, Università di Bologna, via Selmi 3, 40126 Bologna, Italy
}

\section{A R T I C L E I N F O}

Keywords:

Time-scaled phylogeny

Continental vicariance

Divergence times

Social insects

Reproductive system

Asexual queen succession

\begin{abstract}
A B S T R A C T
Termites of the genus Reticulitermes are ecologically and economically important wood feeding social insects that are widespread in the Holarctic region. Despite their importance, no study has yet attempted to reconstruct a global time scaled phylogeny of Reticulitermes termites. In this study, we sequenced mitochondrial (2096 bp) and nuclear (829 bp) loci from 61 Reticulitermes specimens, collected across the genus' entire range, and one specimen of Coptotermes formosanus, which served as an outgroup. Bayesian and Maximum likelihood analyses conducted on the mitochondrial and nuclear sequences support the existence of four main lineages that span four global geographical regions: North America (NA lineage), western Europe (WE lineage), a region including eastern Europe and western Asia (EA + WA lineage), and eastern Asia (EA lineage). The mitochondrial data allowed us to clarify the phylogenetic relationships among these lineages. They were also used to infer a chronogram that was time scaled based on age estimates for termite fossils (including the oldest Reticulitermes fossils, which date back to the late Eocene early Oligocene). Our results support the hypothesis that the extant Reticulitermes lineage first differentiated in North America. The first divergence event in the ancestral lin eage of Reticulitermes occurred in the early Miocene and separated the Nearctic lineages (i.e., the NA lin eages) from the Palearctic lineages (i.e., WE, EE + WA, and EA lineages). Our analyses revealed that the main lineages of Reticulitermes diversified because of vicariance and migration events, which were prob ably induced by major paleogeographic and paleoclimatic changes that occurred during the Cenozoic era. This is the first global and comprehensive phylogenetic study of Reticulitermes termites, and it provides a crucial foundation for studying the evolution of phenotypic and life history traits in Reticulitermes. For instance, the phylogeny we obtained suggested that 'asexual queen succession', a unique reproductive system, independently evolved at least three times during the diversification of the genus.
\end{abstract}

\section{Introduction}

Reticulitermes Holmgren, 1913 is a Holarctic genus of subter ranean termites (Isoptera: Rhinotermitidae) that is widespread and abundant in temperate regions where their biomass can approach that of many termite taxa living in tropical regions (Bignell and Eggleton, 2000; Gentry and Whitford, 1982). These eusocial wood feeding insects are ecologically important in their habitats because they participate in the decomposition of large quantities of organic matter (Bignell and Eggleton, 2000). However, Reticulitermes termites also frequently attack wooden structures

\footnotetext{
This paper was edited by the Associate Editor S.L. Cameron.

* Corresponding author at: Institut de Recherche sur la Biologie de l'Insecte, UMR CNRS 7261, Université de Tours, Faculté des Sciences, Parc de Grandmont, 37200 Tours, France. Fax: +33(0)2 47366966.

E-mail addresses: franck.dedeine@univ-tours.fr (F. Dedeine), simon.dupont@ univ-tours.fr (S. Dupont), sylv.guyot@orange.fr (S. Guyot), kenjijpn@kais.kyoto-u.ac. jp (K. Matsuura), cwang@aesop.rutgers.edu (C. Wang), habibpour_b@scu.ac.ir (B. Habibpour), bagneres@univ-tours.fr (A.-G. Bagnères), barbara.mantovani@ unibo.it (B. Mantovani), andrea.luchetti@unibo.it (A. Luchetti).

1 These authors contributed equally to the study.
} 
and therefore have major economic impacts. Damage caused by and pest control efforts aimed at Reticulitermes and its closest living relative, Coptotermes, are estimated to cost nearly $\$ 11$ billion per year in the United States alone (Su, 2002). The ecological and economic importance of Reticulitermes has spurred a substantial amount of research on various subjects, including termite phylogeography and population genetics (Kutnik et al., 2004; Lefebvre et al., 2008; Leniaud et al., 2010; Luchetti et al., 2007, 2013a; Perdereau et al., 2013, 2015; Uva et al., 2004; Vargo and Husseneder, 2009; Velonà et al., 2010; Ye et al., 2004), caste differentiation and reproductive systems (Matsuura, 2011; Matsuura et al., 2009; Miura and Scharf, 2011), behavioral ecology and chemical communication (Bagnères and Hanus, 2015), as well as gut microbial ecology and nutritional physiology (Bignell, 2011; Brune, 2014; Ohkuma and Brune, 2011).

The genus Reticulitermes belongs to the Rhinotermitidae family; its closest living relatives are the genera Coptotermes and Heterotermes (Bourguignon et al., 2015; Cameron et al., 2012; Inward et al., 2007; Lo et al., 2004; Thompson et al., 2000). To date, 138 extant Reticulitermes species have been described (Krishna et al., 2013). The oldest Reticulitermes fossils were found in Baltic amber deposits and have an estimated age of $\sim 38$ million years, which means they date back to the late Eocene (Emerson, 1971; Engel et al., 2007, 2009). The vast majority of contemporary species identified so far have been collected in western Europe, North America (in the USA), or in eastern Asia (mostly in Japan and China). Almost all phylogenetic and phylogeographic studies have dealt with taxa collected in one of these geographic regions and have focused on either European (Austin et al., 2007, 2002; Jenkins et al., 2001; Kutnik et al., 2004; Lefebvre et al., 2008; Leniaud et al., 2010; Luchetti et al., 2007, 2013a, 2004; Marini and Mantovani, 2002; Uva et al., 2004; Velonà et al., 2010), North American (Austin et al., 2007; Copren et al., 2005; Ye et al., 2004), or Japanese taxa (Kim et al., 2012; Park et al., 2006). Only a few studies have investigated the phylogenetic relationships among European, North American and Asian taxa in targeted analyses (Austin et al., 2004, 2002). However, these previous studies examined a single mitochondrial region (cytochrome oxidase II), which yielded insufficient phylogenetic information. Despite the importance, diversity, and wide distribution of Reticulitermes termites, phylogenetic relationships among the taxa composing the genus are poorly characterized. Furthermore, to date, no study has attempted to analyze the global timing of diversification.

To study the evolutionary changes that occurred during the diversification of this lineage, it is crucial to obtain a reliable phylogeny for Reticulitermes. Many phenotypic and life history traits are known to vary among Reticulitermes species. These traits include characteristics related to social organization, such as reproductive systems (Matsuura, 2011) and colony breeding structures (Vargo and Husseneder, 2009); chemical cues involved in interindividual recognition (Bagnères and Hanus, 2015); or assemblages of gut microorganisms that are essential for lignocellulose digestion (Hongoh et al., 2005). A better understanding of the phylogenetic relationships among Reticulitermes species will make it easier to assess this variation from an evolutionary perspective. For instance, some Reticulitermes species employ a unique reproductive system called asexual queen succession (AQS). In species displaying $A Q S$, queens produce neotenic replacement queens by parthenogenesis but use normal sexual reproduction to produce other colony members (Matsuura et al., 2009). Although it has been argued that AQS may provide selective advantages over non AQS forms at both the colony and individual levels (Matsuura, 2011), this phenotype does not occur in all Reticulitermes species. AQS has been observed in three (R. speratus, $R$. virginicus and $R$. lucifugus) of the nine Reticulitermes species examined for this system to date (Huang et al., 2013; Kobayashi et al., 2013; Luchetti et al., 2013b;
Matsuura et al., 2009; Vargo et al., 2012; Wu et al., 2013). The fact that species exhibiting AQS do not seem to be closely related suggests that this reproductive system has been independently acquired (or lost) several times during the diversification of Reticulitermes. Detailed information on the phylogenetic relation ships among species in this genus could clarify this issue, and therefore provide crucial knowledge for studying the conditions under which AQS evolved, persisted or disappeared.

The first goal of this study was to use DNA sequence data obtained from two coding mitochondrial regions (cytochrome oxidases I and II [COI and COII]), one non coding mitochondrial region (16S rRNA) and two non coding nuclear regions (ribosomal DNA Internal Transcribed Spacer 1 and 2 [ITS1 and ITS2]) to resolve the phylogenetic relationships among the main lineages and species of Reticulitermes. The second goal was to estimate the time frame in which the genus diversified, in order to correlate cladoge netic events with known palaeogeographic and palaeoclimatic events. This study provides the first comprehensive phylogenetic analysis of Reticulitermes termites. Results are discussed in the context of termite historical biogeography and taxonomy, and the evolution of AQS is also addressed.

\section{Materials and methods}

\subsection{Taxon sampling}

Sixty one colonies of Reticulitermes species and one colony of Coptotermes formosanus Shiraki were sampled for this study. Samples were collected between 1998 and 2013 in five major geographic regions of the world: North America (five US states: Louisiana, Florida, Georgia, California, and Mississippi), western Europe (France, Spain, and Italy), eastern Europe (Greece, Crete, and the Cyclades), western Asia (Israel, Turkey, Cyprus and Iran), and eastern Asia (China and Japan) (Table 1). Sampled individuals were preserved in $96 \%$ or absolute ethanol and stored at $4{ }^{\circ} \mathrm{C}$ or room temperature until DNA extraction. Specimens of described species were identified using morphological, chemical or molecular criteria (Clément et al., 2001; Ye et al., 2004). Non identified specimens were designated as " $R$. sp.", followed by a reference number. In this study, eight samples could not be identified ( $R$. sp. 1 through $R$ sp. 8; Table 1 ).

\subsection{Molecular procedures}

Genomic DNA was extracted from one worker per colony using standard phenol-chloroform purification (Kutnik et al., 2004) or the Wizard ${ }^{\circledR}$ Genomic DNA Purification Kit (Promega). Three mitochondrial loci, COI (723 bp), COII (658 bp), and 16S rRNA (715 bp), and two nuclear loci, ITS1 (471 bp) and ITS2 (358 bp), were amplified using PCR. Amplifications were performed using DreamTaq ${ }^{\circledR}$ PCR Master Mix (Thermo Scientific). An initial denaturing step at $95^{\circ}$ $\mathrm{C}(2 \mathrm{~min})$ was followed by 35 iterations of the following cycles: $94{ }^{\circ} \mathrm{C}$ (30 s), annealing temperature (30 s), and $72{ }^{\circ} \mathrm{C}(1 \mathrm{~min})$. The extension step took place at $72{ }^{\circ} \mathrm{C}(10 \mathrm{~min})$. Information on the primers and annealing temperatures used is provided in Table 2. ITS1 primers were designed using Primer 3 (V0.9) for the 18S (ITS1F) and the 5.8S (ITS1R) portions of the nuclear ribosomal RNA gene of Blattella germanica (Genbank accession number: AF321214)(Mukha et al., 2002). Similarly, the reverse primer for the 16S gene (16SR1) was designed using the $16 \mathrm{~S}$ mitochondrial ribosomal RNA gene of Reticulitermes santonensis (synonymous with $R$. flavipes; Genbank accession number: AF262589) (Thompson et al., 2000). The PCR products were purified and sequenced using Big Dye 3.1 and a 96 capillary ABI 3730xl sequencing system (Applied Biosys tems). Sequences were inspected, corrected and aligned using the 
Table 1

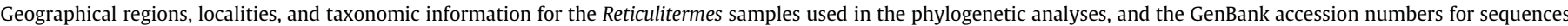
obtained in this study. Samples $R$. sp. 1 to $R$. sp. 8 are unidentified species.

\begin{tabular}{|c|c|c|c|c|c|c|c|}
\hline Geographical region & Taxon & Sampling location & Code & $16 S$ & $\mathrm{COI}$ & COII & ITS1/ITS2 \\
\hline \multicolumn{8}{|l|}{ North America (NA) } \\
\hline & R. flavipes & New Orleans, Louisiana, USA & NEO & KM245639 & KM245702 & KM245765 & KM245828 \\
\hline & $R$ flavipes & Gainesville, Florida, USA & GAI & KM245640 & KM245703 & KM245766 & KM245829 \\
\hline & $R$. flavipes & Ile d'Oléron, France ${ }^{\mathrm{a}}$ & OLE & KM245641 & KM245704 & KM245767 & KM245830 \\
\hline & R. hageni & Athens, Georgia, USA & ATH & KM245642 & KM245705 & KM245768 & KM245831 \\
\hline & $R$. hesperus & Placerville, California, USA & PVI & KM245643 & KM245706 & KM245769 & KM245832 \\
\hline & R. hesperus & Novato, California, USA & NOV & KM245644 & KM245707 & KM245770 & KM245833 \\
\hline & R. malletei & Picayune, Mississippi, USA & PIC & KM245645 & KM245708 & KM245771 & KM245834 \\
\hline & R. nelsonae & Fontainebleau Park Forest, Louisiana, USA & FON & KM245646 & KM245709 & KM245772 & KM245835 \\
\hline & R. nelsonae & Paynes Prairies State Park, Florida, USA & PAY & KM245647 & KM245710 & KM245773 & KM245836 \\
\hline & R. virginicus & New Orleans, Louisiana, USA & NEO & KM245648 & KM245711 & KM245774 & KM245837 \\
\hline & R. virginicus & Wakulla Spring State Park, Florida, USA & WAK & KM245649 & KM245712 & KM245775 & KM245838 \\
\hline & R. sp. $1^{\mathrm{b}}$ & Placerville, California, USA & PVI & KM245650 & KM245713 & KM245776 & KM245839 \\
\hline & R. sp. 2 & Athens, Georgia, USA & ATH & KM245651 & KM245714 & KM245777 & KM245840 \\
\hline \multicolumn{8}{|l|}{ Western Europe (WE) } \\
\hline & R. banyulensis & Cassis, France & CAS & KM245652 & KM245715 & KM245778 & KM245841 \\
\hline & R. banyulensis & Teruel, Spain & TER & KM245653 & KM245716 & KM245779 & KM245842 \\
\hline & R. grassei & Oléron, France & OLE & KM245654 & KM245717 & KM245780 & KM245843 \\
\hline & R. lucifugus corsicus & Feniglia Natural Reserve, Italy & FEN & KM245655 & KM245718 & KM245781 & KM245844 \\
\hline & R. lucifugus lucifugus & Marseille, France & MAR & KM245656 & KM245719 & KM245782 & KM245845 \\
\hline \multicolumn{8}{|l|}{ Eastern Europe (EE) } \\
\hline & R. balkanensis & Schinias, Greece & $\mathrm{SCH}$ & KM245657 & КМ245720 & KM245783 & KM245846 \\
\hline & R. balkanensis & Nea Makri, Greece & NEM & KM245658 & KM245721 & KM245784 & KM245847 \\
\hline & R. urbis & La Ciotat, France & LAC & KM245659 & KM245722 & KM245785 & KM245848 \\
\hline & R. urbis & Sivota, Greece & SIV & KM245660 & KM245723 & KM245786 & KM245849 \\
\hline & R. urbis & Areopolis, Greece & ARE & KM245661 & KM245724 & KM245787 & KM245850 \\
\hline & R. sp. $3^{\mathrm{c}}$ & Georgioupoli, Crete, Greece & GEO & KM245662 & KM245725 & KM245788 & KM245851 \\
\hline & R. sp. $3^{\mathrm{d}}$ & Kokkino Pyrgos, Crete, Greece & KOK & KM245663 & KM245726 & KM245789 & KM245852 \\
\hline & R. sp. 4 & Amorgos, Cyclades Islands, Greece & AMO & KM245664 & KM245727 & KM245790 & KM245853 \\
\hline \multicolumn{8}{|l|}{ Western Asia (WA) } \\
\hline & R. clypeatus & Ben Shemenn, Israel & BES & KM245665 & KM245728 & КM245791 & KM245854 \\
\hline & R. lucifugus Turkey & Ankara, Turkey & ANK & KM245666 & KM245729 & KM245792 & KM245855 \\
\hline & R. lucifugus Turkey & Konya, Turkey & KON & KM245667 & KM245730 & KM245793 & KM245856 \\
\hline & R. lucifugus Turkey & Mugla, Turkey & MUG & KM245668 & KM245731 & KM245794 & KM245857 \\
\hline & R. sp. 5 & Limassal, Cyprus & CYP & KM245669 & KM245732 & KM245795 & KM245858 \\
\hline & R. sp. 6 & Shahrekord, Iran & IRA & KM245670 & KM245733 & KM245796 & KM245859 \\
\hline \multicolumn{8}{|l|}{ Eastern Asia (EA) } \\
\hline & R. chinensis & Jingmen, Hubei, China & JIN-1 & KM245671 & KM245734 & KM245797 & KM245860 \\
\hline & R. chinensis & Jingmen, Hubei, China & JIN-2 & KM245672 & KM245735 & KM245798 & KM245861 \\
\hline & R. guangzhouensis & Guangzhou, Guangdong, China & GUA & KM245673 & KM245736 & KM245799 & KM245862 \\
\hline & R. kanmonensis & Nanchang, Jiangxi, China & NAC & KM245674 & KM245737 & KM245800 & KM245863 \\
\hline & R. kanmonensis & Yichang, Hubei, China & YIC & KM245675 & KM245738 & KM245801 & KM245864 \\
\hline & R. khaoyaiensis & Nanchang, Jiangxi, China & NAC & KM245676 & KM245739 & KM245802 & KM245865 \\
\hline & R. khaoyaiensis & Nanling, Wuhu, Anhui, China & NAN & KM245677 & KM245740 & KM245803 & KM245866 \\
\hline & R. leptomandibularis & Wanzai, Yichun, Jiangxi, China & WAN & KM245678 & KM245741 & KM245804 & KM245867 \\
\hline & R. sp. 7 & Nanling, Wuhu, Anhui, China & NAN & KM245679 & KM245742 & KM245805 & KM245868 \\
\hline & R. sp. 8 & Guangzhou, Guangdong, China & GUA-1 & KM245680 & KM245743 & KM245806 & KM245869 \\
\hline & R. sp. 8 & Guangzhou, Guangdong, China & GUA-2 & KM245681 & KM245744 & KM245807 & KM245870 \\
\hline & R. amamianus & Yuidake, Amami, Japan & AMA-1 & KM245682 & KM245745 & КМ245808 & KM245871 \\
\hline & R. amamianus & Yuidake, Amami, Japan & AMA-2 & KM245683 & KM245746 & KM245809 & KM245872 \\
\hline & R. amamianus & Kosyuku, Amami, Japan & KOS & KM245684 & KM245747 & KM245810 & KM245873 \\
\hline & R. kanmonensis & Ejio Park, Yamaguchi, Japan & YAM-1 & KM245685 & KM245748 & KM245811 & KM245874 \\
\hline & R. kanmonensis & Ejio Park, Yamaguchi, Japan & YAM-2 & KM245686 & KM245749 & KM245812 & KM245875 \\
\hline & R. miyatakei & Yuwandake, Amami, Japan & AMA-1 & KM245687 & KM245750 & KM245813 & KM245876 \\
\hline & R. miyatakei & Yuwandake, Amami, Japan & AMA-2 & KM245688 & KM245751 & KM245814 & KM245877 \\
\hline & R. okinawanus & Yona, Kunikami, Okinawa, Japan & OKI-1 & KM245689 & KM245752 & KM245815 & KM245878 \\
\hline & R. okinawanus & Hedomisaki, Okinawa, Japan & OKI-2 & KM245690 & KM245753 & KM245816 & KM245879 \\
\hline & R. speratus & Ejio Park, Yamaguchi, Japan & YAM & KM245691 & KM245754 & KM245817 & KM245880 \\
\hline & R. speratus & Handayama, Okayama, Japan & OKA & KM245692 & KM245755 & KM245818 & KM245881 \\
\hline & R. speratus & Motoyama, Kochi, Japan & KOC & KM245693 & KM245756 & KM245819 & KM245882 \\
\hline & R. speratus & Jigenji, Kagoshima, Japan & KAG & KM245694 & KM245757 & KM245820 & KM245883 \\
\hline & R. speratus & Kamigamo, Kyoto, Japan & KYO & KM245695 & KM245758 & KM245821 & KM245884 \\
\hline & R. speratus & Sapporo, Hokkaido, Japan & HOK & KM245696 & KM245759 & KM245822 & KM245885 \\
\hline & R. speratus & Tsukuba, Ibaraki, Japan & IBA & KM245697 & KM245760 & KM245823 & KM245886 \\
\hline & R. speratus & Shibukawa, Gunma, Japan & GUN & KM245698 & KM245761 & KM245824 & KM245887 \\
\hline & R. yaeyamanus & Iriomote, Okinawa, Japan & OKI & KM245699 & KM245762 & KM245825 & KM245888 \\
\hline \multicolumn{8}{|l|}{ Outgroup } \\
\hline & C. formosanus & St Gabriel, Louisiana, USA & - & KM245700 & KM245763 & KM245826 & KM245889 \\
\hline
\end{tabular}

\footnotetext{
sp. CAB in Copren et al. (2005).

c Crete - Group 4 in Velonà et al. (2010).

d Crete - Group 2 in Velonà et al. (2010).
}

${ }^{a}$ Samples of non-native French species (R. flavipes and $R$. urbis) introduced to France (Leniaud et al., 2010; Perdereau et al., 2013). ${ }^{\mathrm{b}} R$. 
Table 2

PCR primer sequences, annealing temperatures, and the sources used. Refer to Table 3 for more details on individual loci.

\begin{tabular}{|c|c|c|c|c|c|}
\hline Locus & Primer name & Direction & Sequence $\left(5^{\prime}-3^{\prime}\right)$ & Annealing temperature $\left({ }^{\circ} \mathrm{C}\right)$ & Source \\
\hline $\mathrm{COI}$ & $\begin{array}{l}\text { C1-J-2195 } \\
\text { C1-J-2183 } \\
\text { TL2-N-3014 }\end{array}$ & $\begin{array}{l}\text { Forward } \\
\text { Forward } \\
\text { Reverse }\end{array}$ & $\begin{array}{l}\text { TTGATTCTTTGGTCACCCAGAAGT } \\
\text { CAACACTTATTTTGATTCTTTGG } \\
\text { TCTAATGCATTAATCTGCCATATTA }\end{array}$ & 50 & $\begin{array}{l}\text { Simon et al. (1994) } \\
\text { Simon et al. (1994) } \\
\text { Simon et al. (1994) }\end{array}$ \\
\hline COII & $\begin{array}{l}\text { Modified A-tLeu } \\
\text { TK-N-3785 }\end{array}$ & $\begin{array}{l}\text { Forward } \\
\text { Reverse }\end{array}$ & $\begin{array}{l}\text { CAGATAAGTGCATTGGATTT } \\
\text { GTTTAAGAGACCATTACTTA }\end{array}$ & 52 & $\begin{array}{l}\text { Miura et al.(2000) } \\
\text { Simon et al. (1994) }\end{array}$ \\
\hline $16 S$ & $\begin{array}{l}\text { LR-J-13017 } \\
\text { 16SR1 }\end{array}$ & $\begin{array}{l}\text { Forward } \\
\text { Reverse }\end{array}$ & $\begin{array}{l}\text { TTACGCTGTTATCCCTAA } \\
\text { CCCGATTCTAAAAGGGGCTA }\end{array}$ & 50 & $\begin{array}{l}\text { Kambhampati and Smith (1995) } \\
\text { Present study }\end{array}$ \\
\hline ITS1 & $\begin{array}{l}\text { ITS1F } \\
\text { ITS1R }\end{array}$ & $\begin{array}{l}\text { Forward } \\
\text { Reverse }\end{array}$ & $\begin{array}{l}\text { TCGTAACAAGGTTTCCGTAGG } \\
\text { CAATTTGCTGCGTTCTTCAT }\end{array}$ & 57 & $\begin{array}{l}\text { Present study } \\
\text { Present study }\end{array}$ \\
\hline ITS2 & $\begin{array}{l}\text { ITS2F } \\
\text { ITS2R }\end{array}$ & $\begin{array}{l}\text { Forward } \\
\text { Reverse }\end{array}$ & $\begin{array}{l}\text { TGTGAACTGCAGGACACAT } \\
\text { GCTTAAATTTAGGGGGTAGTC }\end{array}$ & 50 & $\begin{array}{l}\text { Jenkins et al. (2001) } \\
\text { Jenkins et al. (2001) }\end{array}$ \\
\hline
\end{tabular}

a These primers correspond to the locust taxa primers given in Simon et al. (1994).

Clustal $\mathrm{W}$ algorithm implemented in the MEGA v.6 package. The alignments obtained were further inspected and manually edited. All sequences were deposited in GenBank under the accession numbers provided in Table 1.

\subsection{Phylogenetic analyses}

To evaluate possible saturation of the phylogenetic signal in each mtDNA marker dataset, the pairwise proportions of transitions (ts) and transversions (tv) were plotted against the pairwise uncorrected $p$ distances. For the protein coding sequences (COI and COII), we also plotted the proportions of ts and tv occurring at the third codon position against the pairwise uncorrected $p$ distances.

The best substitution model for each of the five loci was determined using MEGA v.6 and employing the Bayesian information criterion (Table 3 ). Phylogenetic trees were estimated utilizing two datasets: (i) the mitochondrial DNA (mtDNA) sequences (COI, COII, and 16S) and (ii) the nuclear DNA (ncDNA) sequences (ITS1 and ITS2). The congruence between the two datasets was tested using the ILD test (Farris et al., 1995), implemented in PAUP*(Swofford, 2001), with 500 bootstrap replicates. For the two data sets, a Maximum likelihood (ML) search and Bayesian inference (BI) were performed using a partitioned dataset (three and two partitions for mtDNA and ncDNA, respectively). Maximum likeli hood trees were calculated using RAxML v. 7.0.3 (Stamatakis, 2006); bootstrap support was estimated using the rapid hill climbing algorithm (Stamatakis et al., 2008 ) on 500 replicates. Fifty percent majority rule consensus trees were obtained using Phyutility v. 2.2.6 (Smith and Dunn, 2008). Bayesian inference was performed using MrBayes v. 3.2.2 (Ronquist et al., 2012). For both datasets, two searches of four chains each were run for 30,000,000 generations; trees were sampled every 500 genera tions. Convergence diagnostics were assessed via the variance of split frequencies $(<0.01), \operatorname{PSRF}(\geqslant 1.00)$ and ESS $(\geqslant 200)$. The first
$10 \%$ of the sample trees were discarded as burnin. The $50 \%$ majority rule consensus tree was obtained via the sumt command, and the maximum clade credibility (MCC) tree was selected using TreeAnnotator v. 1.8 (Drummond and Rambaut, 2007). For the two datasets, the $50 \%$ majority rule consensus tree and the MCC tree topology gave identical results.

Dating of cladogenetic events was performed using BEAST software v. 1.8 (Drummond and Rambaut, 2007) on the mtDNA dataset. The software calculated the tree topology, as well as the posterior probability support and a divergence time estimate for each node. The algorithm was setup to use an uncorrelated, log normal relaxed clock and the birth death speciation process. Two MCMC chains were run for $100,000,000$ generations, starting from a random tree; sampling took place every 500 generations. As the loci examined are all part of the mitochondrial genome, data partitioning was the same as in the BI analysis (unlinked site models and a linked clock model). Chain stationar ity and convergence were reached when ESS $\geqslant 200$. The MCC tree was determined after discarding the first $10 \%$ of the trees obtained (burnin).

For calibration purposes, the following outgroup taxa were added to the dataset: Coptotermes michaelseni, C. lacteus, C. acinaciformis, Heterotermes tenuis, $H$. tenuior, $H$. longiceps, Heterotermes sp., and Schedorhinotermes breinli (Genbank accession numbers are provided in Supplementary Table S1). Two calibration points based on fossil records were applied to the analysis: the old est known Reticulitermes fossils, $R$. minimus, $R$. fossarum, $R$. antiquus and $R$. sp. (minimum age = 38 Ma; Scudder, 1883; Snyder, 1928; Jarzembowski, 1980; Engel et al., 2007), calibrating the node Reticulitermes + Heterotermes + Coptotermes and the oldest Heterotermes fossil, $H$. eocenicus (minimum age $=38 \mathrm{Ma}$; Engel, 2008) calibrating the node Heterotermes + Coptotermes. Prior probability distribution for calibration points was set as exponential with a soft maximum bound of $100 \mathrm{Ma}$ ( $97.5 \%$ of probability distribution, as in Bourguignon et al., 2015).

Table 3

Summary of information on the individual loci and the relative substitution models used in the phylogenetic analyses.

\begin{tabular}{|c|c|c|c|c|c|}
\hline Locus & No. of sites & No. of variable sites (\%) & No. of parsimony-informative sites (\%) & No. of unique sequences & Substitution model \\
\hline $\mathrm{COI}$ & 723 & $214(29.6)$ & $175(24.2)$ & 51 & $\mathrm{TN} 93+\mathrm{G}+\mathrm{I}$ \\
\hline COII & 658 & $232(35.2)$ & $169(25.7)$ & 58 & $\mathrm{HKY}+\mathrm{G}+\mathrm{I}$ \\
\hline $16 S$ & 715 & $187(26.1)$ & $116(16.2)$ & 58 & $\mathrm{HKY}+\mathrm{G}$ \\
\hline ITS1 & 471 & $110(23.3)$ & $37(7.8)$ & 32 & $\mathrm{~T} 92+\mathrm{G}$ \\
\hline ITS2 & 358 & $71(19.8)$ & $25(6.9)$ & 30 & $\mathrm{JC}+\mathrm{G}$ \\
\hline mtDNA dataset & 2096 & $633(30.2)$ & $460(21.9)$ & 62 & n.a. ${ }^{a}$ \\
\hline ncDNA dataset & 829 & $181(21.8)$ & $62(7.5)$ & 37 & n.a. ${ }^{\mathrm{a}}$ \\
\hline
\end{tabular}

\footnotetext{
a Not applicable.
} 


\section{Results}

\subsection{Sequence characteristics and nucleotide variation}

The five target loci were sequenced for all of the 62 termite samples. When the outgroup sample (i.e., Coptotermes formosanus) was excluded, the percentage of variable sites ranged from $19.8 \%$ for ITS2 to $35.2 \%$ for COII (Table 3). For the two protein coding genes, COI and COII, the percentage of variable sites at the third codon position was $87.8 \%$ and $76.7 \%$, respectively. None of the loci analyzed showed transitional or transversional saturation, even when the third codon positions were considered (Supplementary Fig. S1).

\subsection{Phylogenetic analyses}

ML analysis using the mtDNA sequences (Fig. 1) revealed two main lineages of Reticulitermes termites. The first lineage included all the western European (WE) taxa, and the second lineage was divided in two sublineages. The first sublineage grouped together taxa from eastern European (EE) and western Asian (WA) whereas the second sublineage comprised all the taxa from eastern Asian (EA). In this analysis, North American taxa did not group together but instead clustered in multiple lineages at basal positions in the tree. With some exceptions, the BI tree (Fig. 1) was congruent with the ML tree and robust posterior probabilities provided support for the WE, EE + WA, and EA lineages.

The ML and BI analyses conducted on the ncDNA dataset were less informative than those conducted on the mtDNA dataset. The ncDNA based phylogenetic trees indeed contained numerous deep nodes that were poorly supported or not supported at all (Fig. 2). For instances, these analyses did not support the sister relationship between the EE + WA and EA lineages. They also failed to support the WE lineage and the phylogenetic subdivision within the WA lineage. In addition, the topologies of these trees were not congruent with trees obtained on the mtDNA dataset (ILD test $p<$ 0.01 ). For this reason, analyses on the full dataset combining mtDNA and ncDNA sequences were not conducted. Interestingly, however, analyses performed on the ncDNA dataset clarified the phylogenetic status of the North American taxa, which all grouped together in a well supported lineage (NA lineage) (Fig. 2). Altogether, analyses conducted separately with the mtDNA and the ncDNA datasets suggested that NA lineage was the first to diverge in Reticulitermes genus followed by WE lineage before EE + WA and EA lineages. Such relationships between the main lineages of Reticulitermes termites were also supported by the BEAST analysis conducted with the mtDNA dataset (Fig. 3).

The topology within the WE lineage was very well supported and in perfect agreement with previous studies (Clément et al., 2001) (Figs. 1 and 3). Similarly, the topology within the EE + WA lineage was similar to that found in previous studies (Ghesini and Marini, 2012; Luchetti et al., 2007; Uva et al., 2004; Velonà et al., 2010). In this lineage, a well supported group composed of the three $R$. urbis samples had a sister relationship with the WA lineage, and the later was further subdivided in two groups: WA.1 and WA.2. The WA.1 group provided confirmation that a close relationship exists between the northern samples previously called "R. lucifugus Turkey" and samples from the Aegean Islands (Cyclades, Crete, and Cypriot), which were represented in this study by individuals taken from the Cyclades, Crete and Cypriot (Ghesini and Marini, 2012; Velonà et al., 2010). The WA.2 group brought together widely distributed taxa, whose range spanned from northern Iran ( $R$. sp. 6, IRA) to eastern Greece ( $R$. balkanensis); it also included taxa from the eastern Mediterranean such as " $R$. lucifugus Turkey" and R. clypeatus from Israel.
The EA lineage was divided into two groups (Figs. 13 ). The first group, EA.1, included several Japanese taxa collected in southern Japan ( $R$. kanmonensis) and the Ryukyu Islands ( $R$. amaianus, $R$. miyatakei, $R$. okinawanus, and $R$. yaeyamanus) as well as some Chinese taxa (R. khaoyaiensis, $R$. sp. 6, and $R$. sp. 7 ). The ML and BI tree topologies for the EA.1 group were highly congruent. The EA.2 group comprised the Japanese taxon $R$. speratus, whose haplotypes formed two clusters, and the Chinese taxa $R$. chinensis and $R$. leptomandibularis. The internal topology of EA.2 was supported by significant ML bootstrap values. However, the BI posterior probability was not significant for the node linking the sample of $R$. leptomandibularis with those of $R$. chinensis.

\subsection{Dating cladogenetic events}

A chronogram was built solely using the mtDNA dataset (Fig. 3). Fossil based calibration points allowed to retrieve the time estimates of cladogenetic events that mostly occurred between late Paleocene and late Miocene, although a few events also occurred during the Pliocene (Fig. 3). Interestingly, our time estimates were consistent with those obtained by other phylogenetic studies in termites (Bourguignon et al., 2015; Lee et al., 2015). For instance, the divergence of the lineages leading to Reticulitermes genus and to the group comprising both Heterotermes and Coptotermes genera was estimated to have occurred 66.6 Ma (51.2 87.0 Ma 95\% high posterior density [HPD]) in the present study, whereas the same event has been estimated to have occurred about 60 Ma by Bourguignon et al. (2015) and about 50 Ma by Lee et al. (2015). Similarly, the origin of the genus Coptotermes was estimated to have occurred about 20.9 Ma (15.4 28.2 Ma 95\% HPD) in the present study, a time estimates that fully overlapped those found by Lee et al. (2015). These convergent results suggest that the chronogram computed in this study is reliable. This time scaled phylogeny indicated that the Reticulitermes genus started to diversify about 18.4 Ma, a geological period corresponding to the early Miocene (Fig. 3). The NA lineages started to diverge during the same time whereas the WE, EE + WA, and EA lineages started their diversification during the mid or late Miocene.

\subsection{Taxonomy and systematics of Reticulitermes species}

All the Reticulitermes species included in this study, whether described or not, formed well supported lineages in the phylogenetic trees (Figs. 13 ). None of Reticulitermes taxa for which several samples were analyzed $(N=17)$ demonstrated polyphyly or paraphyly. One possible exception was the taxonomic group containing the $R$. nelsonae (FON and PAY) and R. sp. 2 (ATH) samples; however, we cannot exclude the possibility that $R$. sp. 2 was, in fact, a $R$. nel sonae sample.

\section{Discussion}

\subsection{Origin and historical biogeography of the Reticulitermes genus}

The oldest Reticulitermes fossils described so far, namely $R$. antiquus, $R$. minimus, $R$. sp., and $R$. fossarum, date back to the late Eocene (about $38 \mathrm{Ma}$; Figs. 3 and 4a). With the exception of $R$. fossarum, which was discovered in North America (Colorado, USA), most of these fossils were found in Europe (i.e., the Baltics, Russia, Poland, and the United Kingdom), which led Emerson (1971) to propose that the Reticulitermes genus originated in the northern part of the West European platform (Meulenkamp et al., 2000). This hypothesis appears plausible from a climatological perspective because, in the Eocene, the climate at the northern latitudes was tropical (Tertiary Thermal Maximum) (Zachos et al., 2001) 


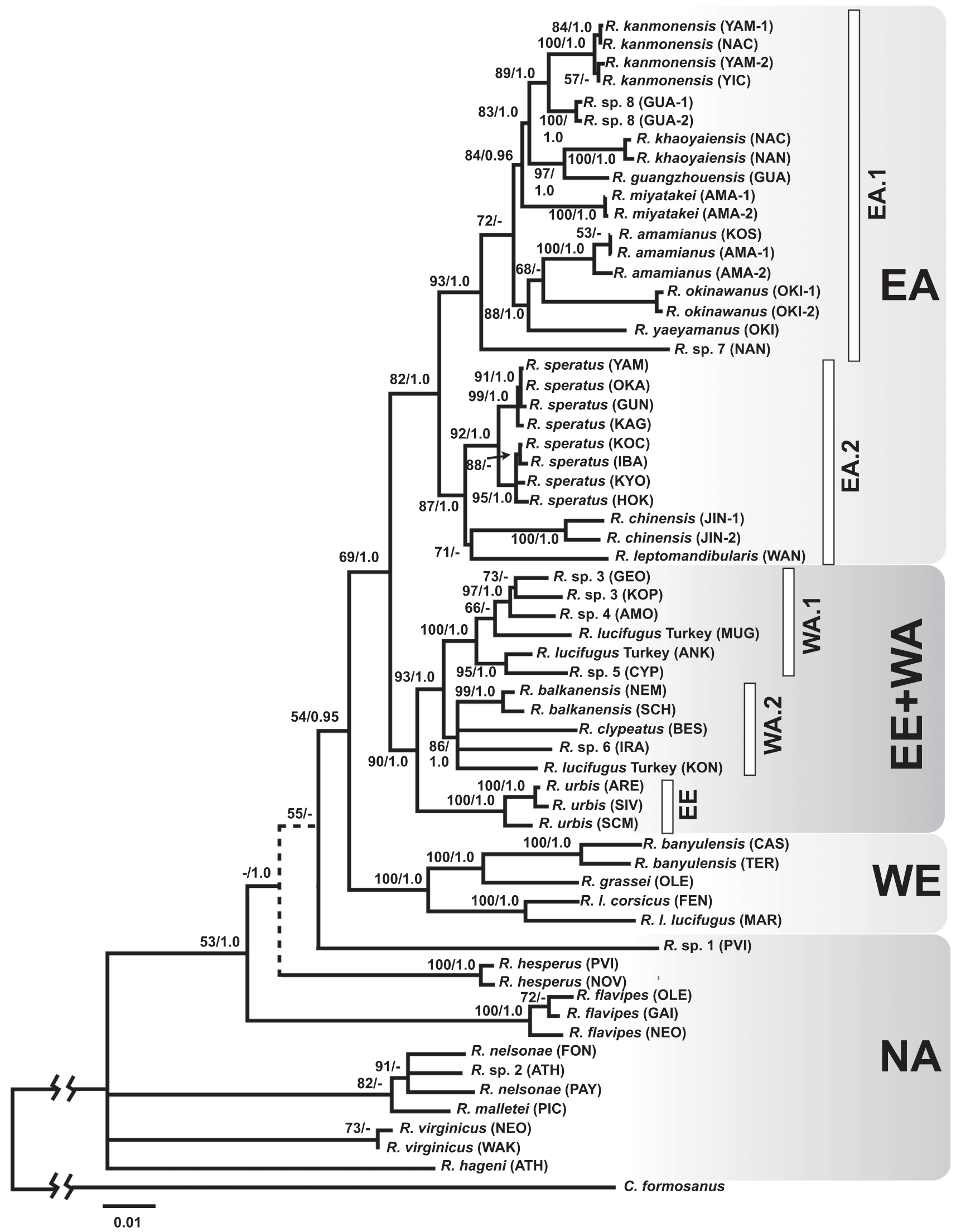

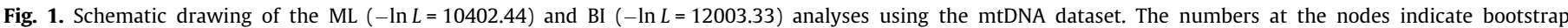

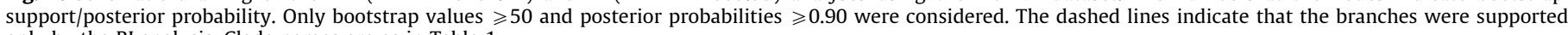
only by the BI analysis. Clade names are as in Table 1 . 


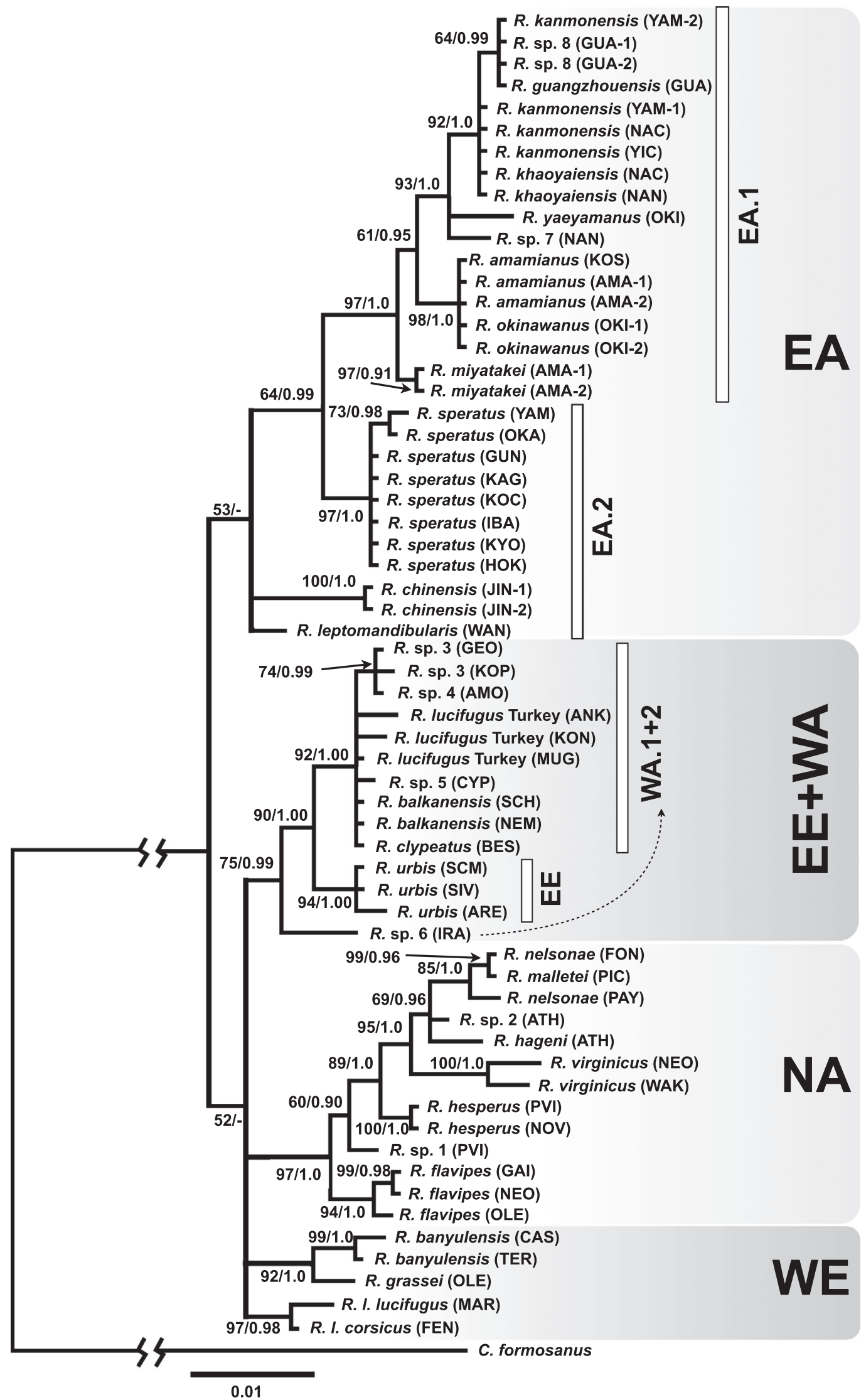

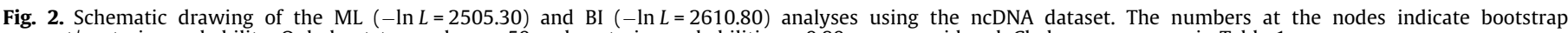
support/posterior probability. Only bootstrap values $\geqslant 50$ and posterior probabilities $\geqslant 0.90$ were considered. Clade names are as in Table 1 . 


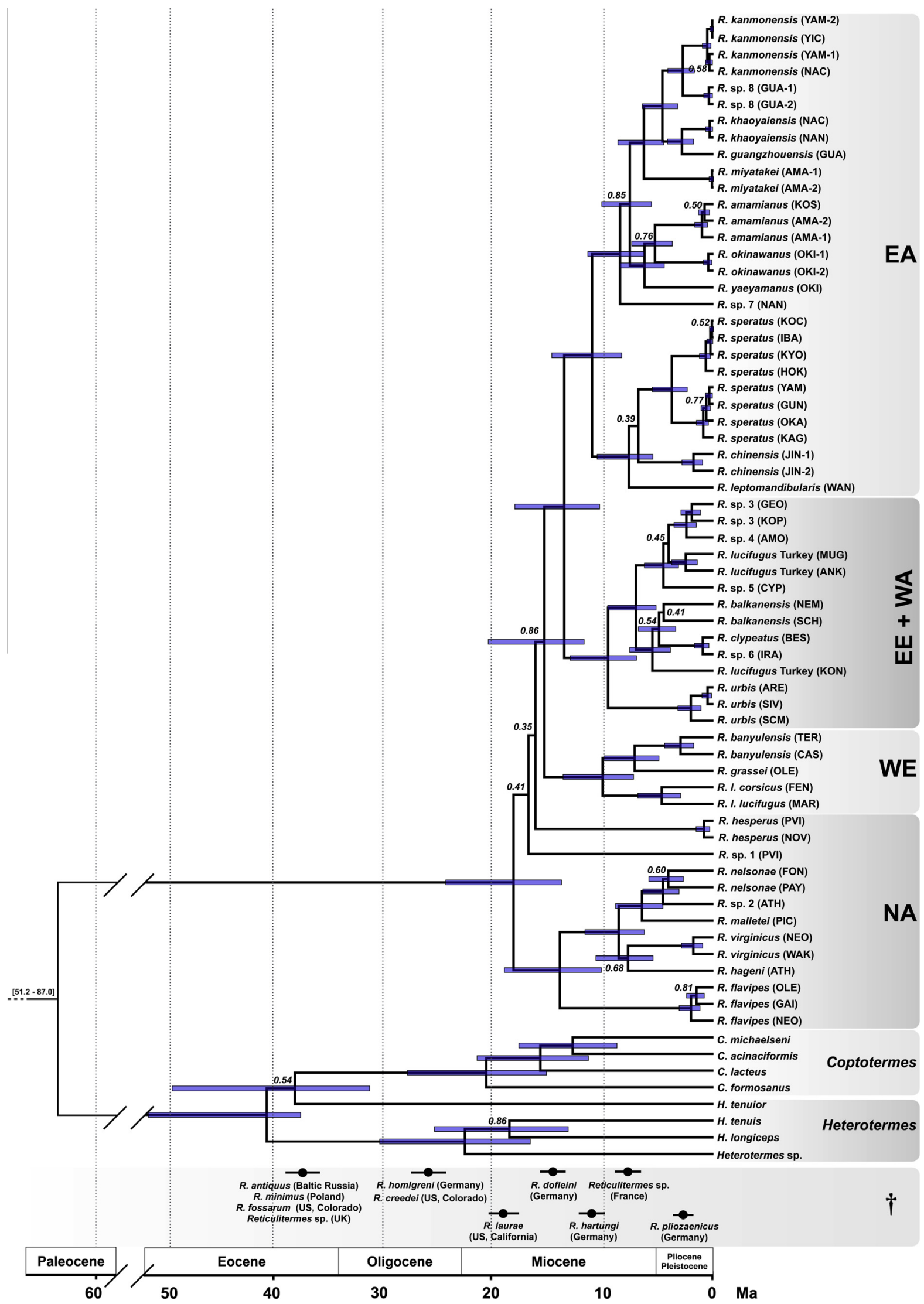

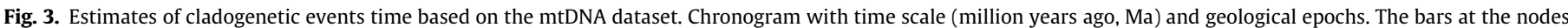

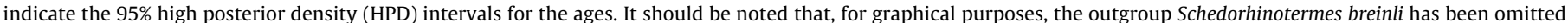

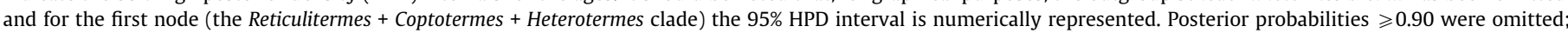

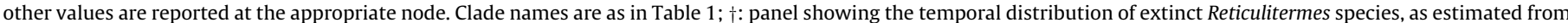
the fossil collections (see Section 2.3 and Krishna et al. (2013) for references). 
(a)

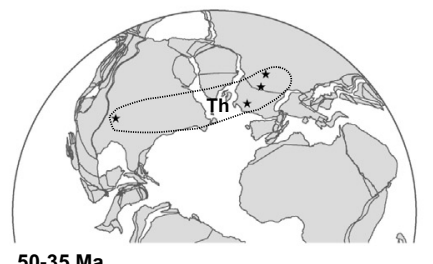

50-35 Ma

(d)

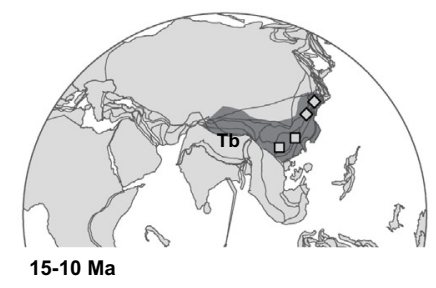

(b)

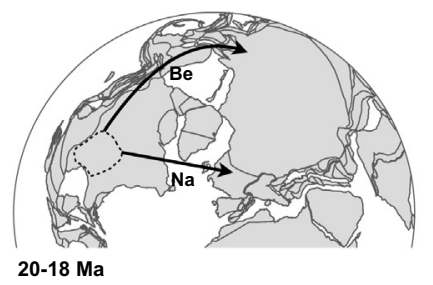

(e)

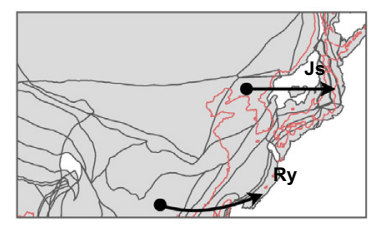

(c)

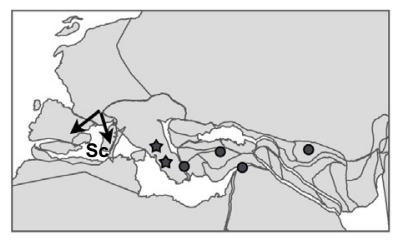

15-10 Ma

10-5 Ma

(f)

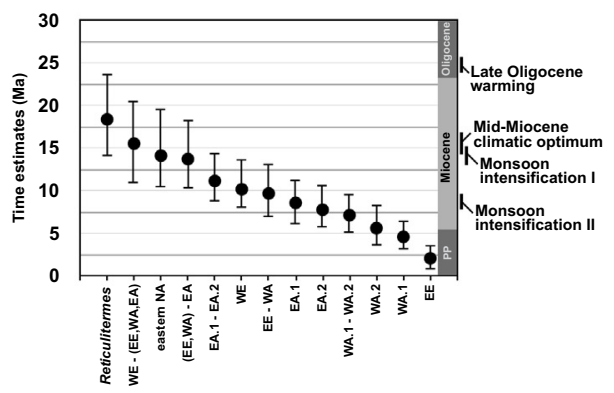

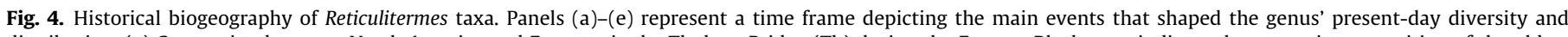

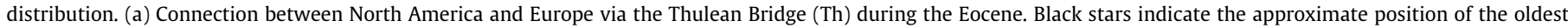

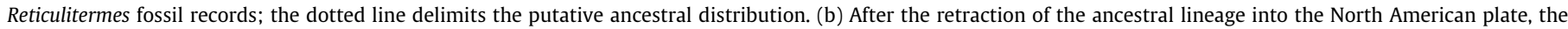

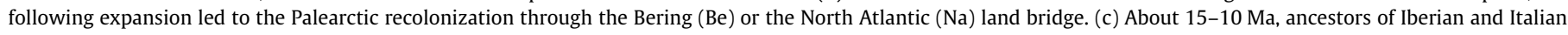

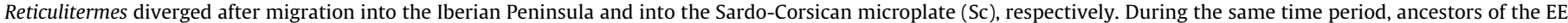

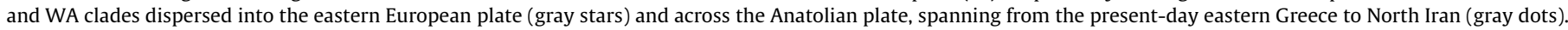

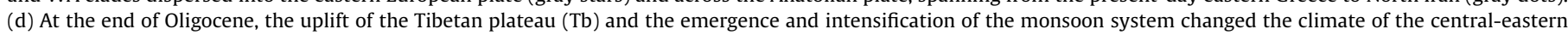

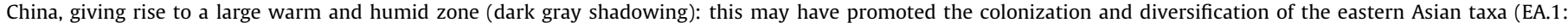

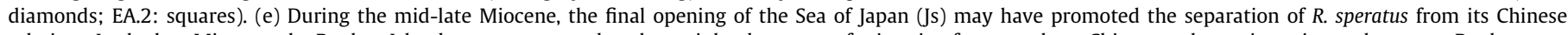

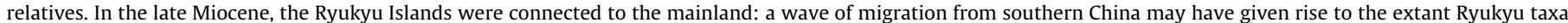

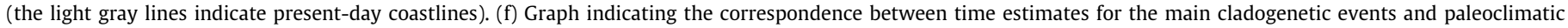

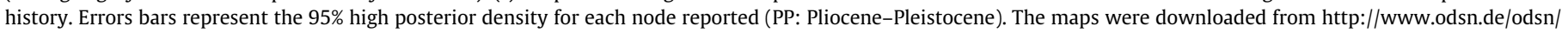
services/paleomap/paleomap.html (Hay et al., 1999) and modified.

and therefore favorable for termites. The distribution of coeval Eocenic Reticulitermes fossils across the Laurasian supercontinent (Fig. 4a) suggests that these termites differentiated well before the separation of North America and Eurasian plates, about $50 \mathrm{Ma}$, when the Thulean land bridge finally disappeared (Sanmartin et al., 2001). In the present analysis, the origin of extant Reticulitermes lineages was however estimated to have occurred during the early Miocene, about 18.4 Ma, definitely later than the minimum age of the oldest fossils. Considering the diversity and distribution of Eocenic taxa and the late Oligocene fossils $R$. creedei (Colorado) and $R$. holmgreni (Germany) (Fig. 3), this temporal shift could be explained by an extensive lineages extinction. This could be indeed related to a major paleoclimatic change at the transition between Eocene and Oligocene when a sudden and deep tempera ture decline occurred (Oi 1 glaciation, about $34 \mathrm{Ma}$; Zachos et al., 2001; Eldrett et al., 2009) and could have caused the extinction of numerous Reticulitermes lineages.

ML, BI and BEAST analyses indicated that the NA taxa do not form a monophyletic group but instead constitute an assemblage of different lineages at the most basal positions of the tree (Figs. 1 and 3). Moreover, beside the ancestral node of all Reticulitermes taxa, the first nodes within the clade are not supported, thus evi dencing a polytomic topology. Although the analyses conducted in this study did not allow the distinction between a hard or a soft polytomy, they nevertheless suggest that all of the extant Reticulitermes taxa used in this study have a North American origin. One plausible hypothesis is that the ancestral lineage retracted into the North America during the $\mathrm{Oi} 1$ glaciation before to start an expansion when global temperatures increased in Oligocene until Mid Miocene, 18.4 and 15.6 Ma (Fig. 4f; Zachos et al., 2001). These events would have driven the diversification of the NA lineages with the eastern taxa ( $R$. flavipes, $R$. virginicus, $R$. hageni, $R$. malletei, $R$. nelsonae and $R$. sp. 2) diverging from the western taxa ( $R$. hesperus and $R$. sp. 1), and to the re-colonization of the Palearctic.

The obtained tree topologies did not allow to identify the routes that have been followed during the Palearctic re colonization. Two hypotheses can be nevertheless proposed (Fig. 4b). The Bering land bridge, connecting the North America and Asia, is considered to have constituted the main route for Holarctic intercontinental dispersals since the early Miocene (Sanmartin et al., 2001). In alternative to the trans beringian route, the Reticulitermes lineage may have experienced a trans Atlantic dispersal (Fig. 4b). The main North Atlantic land bridges, the Thulean bridge (through the British Islands and Greenland) and the De Geer route (through Fennoscandia, Greenland and Canadian Islands) are indeed known to have disappeared in the Mid Eocene (Sanmartin et al., 2001; Brikiatis, 2014). However, recent geological surveys have suggested the existence of another North Atlantic land connections during Miocene that lasted until 20 Ma (Ellis and Stoker, 2014). Recent palynological, fossil and molecular phylogenetic analyses on plants (Grimsson and Denk, 2005; Tiffney, 2008; Denk et al., 2010, 2015) and on freshwater fishes (i.e., Perca and Sander)(Haponski and Stepien, 2013; Stepien et al., 2015) concluded that a land bridge, or at least a stepping stone islands path, connecting North America and Western Europe still existed during Miocene.

During the Mid Miocene, approximately 15.5 Ma, the Palearctic lineage split into the western European lineage and the eastern Palearctic lineages (Fig. 3). In the case of the western European lineage, we can speculate that some populations migrated toward the southern West European plate (Meulenkamp and Sissingh, 2003; 
Meulenkamp et al., 2000), subsequently diverging into the Iberian (i.e., R. grassei and R. banyulensis)(Kutnik et al., 2004) and the Italian (i.e., $R$. l. lucifugus and $R$. l. corsicus) taxa. In this study, the divergence between Iberian and Italian taxa was estimated to have occurred about $10.2 \mathrm{Ma}$, much later than previously thought. In this context, a recent study based on both phylogenetic relation ships and biogeographic data, proposed that the ancestor of the Italian lineage diverged when the Sardo Corsican microplate detached from the Iberian Peninsula, about $25 \mathrm{Ma}$ (Luchetti et al., 2013a). Because biogeographic based divergence times are usually much less precise than fossil calibrated time trees, however, the time estimates obtained in the present study are probably more reliable. Considering the closer relationship between the Iberian $R$. grassei and the Sardo Corsican Italian subspecies $R$. $l$. corsicus (Luchetti et al., 2013), the following scenario can be suggested. During the anti clockwise rotation, the Sardo Corsican microplate remained connected to the mainland through a land bridge until the late Miocene early Pliocene (Meulenkamp and Sissingh, 2003). During the southward migration of the West European lineage, it is likely that some populations migrated within the SardoCorsican microplate through the land bridge and constituted the ancestor populations of the Italian $R$. lucifugus complex (Fig. 4c). A similar scenario involving the Sardo Corsican connection with the mainland has been proposed for land snail species of the genus Solatopupa (Ketmaier et al., 2006).

Our results indicate that the eastern European and western Asian lineages (EE and WA) may have diverged from the eastern Asian lineage (EA) around 13.7 Ma. During this time, the climate reached a warm optimum around $1614 \mathrm{Ma}$ (Fig. 4f) while the future Mediterranean area underwent to great tectonic move ments (Zachos et al., 2001; Meulenkamp and Sissingh, 2003). These new paleoclimatic and paleogeographic conditions possibly favored the colonization of the eastern European landmasses and the Asian plate. During these migration events, two main lineages may have differentiated: one lineage splitting into the eastern European and western Asian lineages (EE and WA) and the other becoming the eastern Asian lineage (EA).

The chronogram indicates that the eastern European and western Asian (EE + WA) lineage diversified 9.7 Ma (Fig. 3). Some populations of the ancestral lineage likely differentiated into $R$. urbis, whereas other populations would have dispersed between North Iran and East Greece, across the Anatolian plate, and formed several western Asian taxa, including $R$. balkanensis, $R$. clypeatus and at least four other unidentified species (Figs. 3 and 4c). This scenario is consistent with the paleogeographic and biogeographic data. First, the future Balkan peninsula was connected to the Ana tolian plate (separating the Tethys and the Peritethys) until 9.0 Ma (i.e., upon the final opening of the mid Aegean trench)(Meulenkamp, 1985; Meulenkamp and Sissingh, 2003; Rögl, 1999; Velonà et al., 2010). Second, the current natural distribution of $R$. urbis ranges from Peloponnisos to the Slovenian coasts (Luchetti et al., 2007). Therefore, this taxon is the westernmost representative of the EE + WA lineage.

The radiation of the EA lineage started around 11.2 Ma (Fig. 3). The first divergence event involved the EA. 1 lineage, which includes termites found in China and on the Ryukyu Islands, and the EA.2 lineage, which includes the Japanese $R$. speratus and the Chinese $R$. chinensis and $R$. leptomandibularis. Based on present day biogeographic data, it is possible that EA.1 and EA.2 represent southern and northern lineages, respectively. Interestingly, palynological evidence indicates that, until the late Oligocene, an arid area stretched from western to eastern China, which created separate warm and humid regions in the north and south. Later, at the Oligocene Miocene boundary, a monsoon system formed, which intensified two times around $15 \mathrm{Ma}$ and $8 \mathrm{Ma}$ (Fig. 4f), and the humid zone widened, spanning from southern to northeastern
China (Sun and Wang, 2005; Wang, 2013). These paleoclimatic and paleoecological changes would have promoted colonization by termite populations; the evolutionary divergence of the EA.1 and EA.2 lineages may have then followed (Fig. 4d). Furthermore, during the same time period (around $15 \mathrm{Ma}$ ), the western margin of the Asian plate finally broke up and the Japanese sea opened (Jolivet et al., 1994; Maruyama et al., 1997). This event could have started to a vicariant separation between populations, which may have resulted, finally, in the divergence of $R$. speratus from $R$. chinensis and R. leptomandibularis around $87 \mathrm{Ma}$ (Fig. 4e).

The diversification pattern of the EA.1 lineage appears to be more complex, especially that of the Ryukyu species $R$. amamianus, $R$. miyatekei, $R$. okinawanus and $R$. yaeyamanus. The paleogeography of the Ryukyu islands is complicated, but the general consensus is that the islands originated in the late Miocene and were connected to the mainland at some point during the Mio Pliocene and again during the Pleistocene (Kizaki, 1986; Ota, 1998). Many animal taxa underwent differentiation in this area during the Pliocenic fragmentation of the Ryukyus, well after the submergence of the MioPliocenic land bridge (Grismer et al., 1994; Maekawa et al., 1999; Maekawa and Matsumoto, 2003; Ota, 1998). However, our analyses point to an earlier origin for the Ryukyu taxa, suggesting that their diversification took place before the separation of the island arc from the mainland (Fig. 4e). This fits with a polyphyletic origin for the Ryukyu Reticulitermes: $R$. miyatakei is more closely related to the Chinese taxa than to the other Ryukyu or Japanese taxa. Interestingly, a recent study on geckos from the central Ryu kyu islands also found evidence for a Mid Miocene lineage splitting that occurred well before land fragmentation (Honda et al., 2014).

It is worth noting that, in general, most cladogenetic events within the main Reticulitermes lineages occurred in the Miocene (Fig. 3) and have mostly been driven by paleoclimatic and paleo geographic events. After the Late Oligocene warming ( $25 \mathrm{Ma})$ and following the Mid Miocene climatic optimum ( $15 \mathrm{Ma}$ )(Zachos et al., 2001), global temperatures started to fall again. Therefore, this global cooling could have caused populations to migrate to warmer regions, thus further promoting recent diversi fication events.

\subsection{Considerations on taxonomy and systematics}

Our findings largely fit with what is already known about the taxonomy and systematics of Reticulitermes, especially for the North American (Copren et al., 2005; Ye et al., 2004) and western European (Clément et al., 2001; Luchetti et al., 2013a; Velonà et al., 2010) taxa. In addition, some of our results provide support for hypotheses regarding the taxonomic status of certain Asian taxa. For instance, our results revealed that $R$. chinensis and $R$. leptomandibularis are closely related, which supports their previous classification as subspecies (Krishna et al., 2013). Our results also confirmed that the Japanese species, $R$. speratus, is composed of two main lineages that may be subspecies (Kim et al., 2012; Park et al., 2006). However, our study also highlights the need for fur ther research into the taxonomy and systematics of the genus Reticulitermes. It is particularly necessary for the eastern European and western Asian lineages (EE + WA), for which only three of ten taxa (i.e., R. urbis, R. balkanensis, and R. clypeatus) have been described at the species level. Furthermore, some of the names given to these undescribed taxa are misleading and should be avoided in future studies. For instance, the name " $R$. lucifugus Turkey", which has been given to distinct taxa in the EE + WA lineage, should no longer be used since it refers to the "true" $R$. lucifugus species complex, which belongs to the WE lineage (Figs. 14 ). It is also worth noting that introgressive hybridization might occur among Reticulitermes taxa. In this study, introgression is indeed suggested by the sample collected in Iran (R. sp. 6, IRA), which exhibited a different position 
in the phylogenies obtained using the mtDNA versus the ncDNA dataset (Figs. 1 and 2).

The present study also supports the idea that many previously described species are in fact synonymous. For example, out of the 138 Reticulitermes species described thus far (Krishna et al., 2013), 119 species are from China. This number is probably largely overestimated and may not reflect the true species diversity of this region. Many Chinese Reticulitermes specimens have been described exclusively using morphological characters. Future taxonomic studies should therefore combine morphological approaches with molecular tools.

\subsection{Evolution of asexual queen succession (AQS) in Reticulitermes}

Our findings showed that the three Reticulitermes species exhibiting AQS (i.e., $R$. speratus, $R$. virginicus and $R$. lucifugus) do not form a monophyletic group but, instead, belong to three distinct phylogenetic lineages (i.e., EA, NA and WE) (Figs. 3 and 5). These results also revealed that Reticulitermes species exhibiting AQS are closely related to species in which AQS was not found. The best hypothesis to explain these results is that AQS was originally absent in the ancestral lineage of Reticulitermes but evolved at least three times independently during the diversification of the genus. If we consider this hypothesis to be true, our analyses allow us to estimate the time periods during which AQS evolved. In the eastern Asia lineage, $R$. speratus expresses AQS, but six other species, namely $R$. kanmonensis, $R$. miyatakei, $R$. amamianus, $R$. okinawanus, $R$. yaeyamanus (Kawatsu and Matsuura, 2013) and $R$. chinensis (Huang et al., 2013) do not. Because $R$. chinensis, the closest relative of $R$. speratus, does not exhibit AQS, this trait may have evolved in EA less than 7.8 6.9 Ma (Fig. 4), when the EA.2 lin-

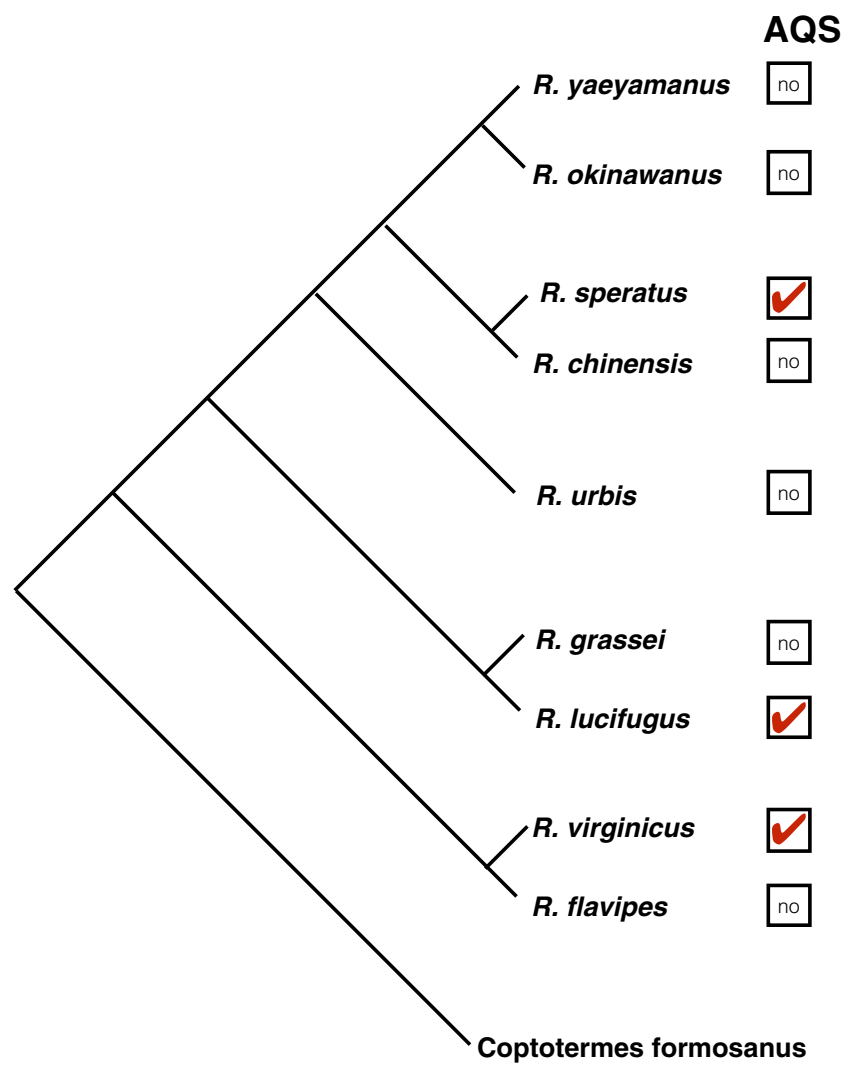

Fig. 5. Cladogram of Reticulitermes species that have been examined for the presence of asexual queen succession (AQS). AQS seems to have independently evolved three times in Reticulitermes. AQS has not been detected in the outgroup Coptotermes formosanus. eage diverged into $R$. speratus and $R$. chinensis/R. leptomandibularis. Both of the two $R$. speratus lineages, which diversified around 3.8 Ma, express AQS. Thus, AQS seems to have evolved before then in the eastern Asian lineage. In the western European lineage (WE), $R$. lucifugus appears to have diverged from $R$. grassei populations 10.2 Ma, and the divergence between the subspecies $R$. l. lucifugus and $R$. l. corsicus likely occurred about $4.7 \mathrm{Ma}$. Because both of the $R$. lucifugus subspecies exhibit AQS (Luchetti et al., 2013b) and $R$. grassei does not (F. Dedeine, unpublished data), AQS may have evolved in the WE lineage between 10.2 and $4.7 \mathrm{Ma}$. In the North American lineage (NA), $R$. flavipes has diverged from $R$. virginicus around 14.1 Ma. Because $R$. virginicus displays AQS but $R$. flavipes does not, AQS may have evolved in the NA lineage less than 14.1 Ma.

Although more empirical studies are required to test the hypothesis of an independent evolution of AQS in Reticulitermes termites, it is interesting to note that AQS was recently reported in the higher termite species Cavitermes tuberosus (Roisin et al., 2014) and Embiratermes neotenicus (Fougeyrollas et al., 2015), suggesting that AQS might be much more widespread in termites than previously thought, and that it evolved independently in at least two different termite families (Fougeyrollas et al., 2015).

\section{Acknowledgments}

We would like to thank Omar Rota Stabelli for fruitful discussions and his help with the phylogenetic analyses. We also thank Mario Marini for the termite samples from Crete and Kirsten Copren for the samples from California. We wish to acknowledge Jessica Pearce for the English revision of the manuscript, and Guillaume Baudouin for his help in drawing the graphical abstract. This work was supported by a French ANR grant obtained by F. Dedeine (EvoSymTer 08 JCJC 007601) as well as an Italian RFO UNIBO and Canziani funding obtained by B. Mantovani and A. Luchetti.

\section{Appendix A. Supplementary material}

Supplementary data associated with this article can be found, in the online version, at http://dx.doi.org/10.1016/j.ympev.2015.10. 020 .

\section{References}

Austin, J.W., Bagnères, A.G., Szalanski, A.L., Scheffrahn, R.H., Heintschel, B.P. Messenger, M.T., Clement, J.L., Gold, R.E., 2007. Reticulitermes malletei (Isoptera: Rhinotermitidae): a valid nearctic subterranean termite from eastern North America. Zootaxa, 1-26.

Austin, J.W., Szalanski, A.L., Cabrera, B.J., 2004. Phylogenetic analysis of the subterranean termite family Rhinotermitidae (Isoptera) by using the mitochondrial cytochrome oxidase II gene. Ann. Entomol. Soc. Am. 97, 548-555.

Austin, J.W., Szalanski, A.L., Uva, P., Bagneres, A.G., Kence, A., 2002. A comparative genetic analysis of the subterranean termite genus Reticulitermes (Isoptera: Rhinotermitidae). Ann. Entomol. Soc. Am. 95, 753-760.

Bagnères, A.-G., Hanus, R., 2015. Communication and Social Regulation in termites. In: Aquiloni, L., Tricarico, E. (Eds.), Social recognition in invertebrates: the knowns and the unknowns. Springer, in press.

Bignell, D.E., 2011. Morphology, physiology, biochemistry and functional design of the termite gut: an evolutionary wonderland. In: Bignell, D.E., Roisin, Y., Nathan, L. (Eds.), Biology of Termites: A Modern Synthesis. Springer, pp. 375-412.

Bignell, D.E., Eggleton, P., 2000. Termites in ecosystems. In: Abe, T., Bignell, D.E., Higashi, M. (Eds.), Termites: Evolution, Sociality, Symbioses, Ecology. Kluwer Acad., pp. 363-387.

Bourguignon, T., Lo, N., Cameron, S.L., Sobotnik, J., Hayashi, Y., Shigenobu, S., Watanabe, D., Roisin, Y., Miura, T., Evans, T.A., 2015. The evolutionary history of termites as inferred from 66 mitochondrial genomes. Mol. Biol. Evol. 32, 406421.

Brikiatis, L., 2014. The De Geer, Thulean and Beringia routes: key concepts for understanding early Cenozoic biogeography. J. Biogeogr. 41, 1036-1054.

Brune, A., 2014. Symbiotic digestion of lignocellulose in termite guts. Nature reviews. Microbiology. 
Cameron, S.L., Lo, N., Bourguignon, T., Svenson, G.J., Evans, T.A., 2012. A mitochondrial genome phylogeny of termites (Blattodea: Termitoidae): robust support for interfamilial relationships and molecular synapomorphies define major clades. Mol. Phylogenet. Evol. 65, 163-173.

Clément, J.L., Bagnères, A.G., Uva, P., Wilfert, L., Quintana, A., Reinhard, J., Dronnet, S. 2001. Biosystematics of Reticulitermes termites in Europe: morphological chemical and molecular data. Insectes Soc. 48, 202-215.

Copren, K.A., Nelson, L.J., Vargo, E.L., Haverty, M.I., 2005. Phylogenetic analyses of mtDNA sequences corroborate taxonomic designations based on cuticular hydrocarbons in subterranean termites. Mol. Phylogenet. Evol. 35, 689-700.

Denk, T., Grimsson, F., Zetter, R., 2010. EPISODIC MIGRATION OF OAKS TO ICELAND: EVIDENCE FOR A NORTH ATLANTIC “LAND BRIDGE” IN THE LATEST MIOCENE.

Am. J. Bot. 97, 276-287.

Denk, T., Velitzelos, D., Guner, H.T., Ferrufino-Acosta, L., 2015. SMILAX SMILACACEAE) FROM THE MIOCENE OF WESTERN EURASIA WITH CARIBBEAN BIOGEOGRAPHIC AFFINITIES. Am. J. Bot. 102, 423-438.

Drummond, A.J., Rambaut, A., 2007. BEAST: Bayesian evolutionary analysis by sampling trees. BMC Evol. Biol. 7.

Eldrett, J.S., Greenwood, D.R., Harding, I.C., Huber, M., 2009. Increased seasonality through the Eocene to Oligocene transition in northern high latitudes. Nature 459, 969-973.

Ellis, D., Stoker, M.S., 2014. The Faroe-Shetland Basin: A Regional Perspective from the Paleocene to the Present Day and its Relationship to the Opening of the North Atlantic Ocean. Geological Society, London, Special Publications 397, pp. 11-31.

Emerson, A.E., 1971. Tertiary fossil species of the Rhinotermitidae (Isoptera) phylgeny of genera, and reciprocal phylogeny of associated Flagellata (Protozoa) and the Staphylinidae (Coleoptera). Bulletin of the American Museum of Natural History 146, 243-304.

Engel, M.S., 2008. Two new termites in Baltic amber (Isoptera). J. Kansas Entomol. Soc. 81, 194-203.

Engel, M.S., Grimaldi, D.A., Krishna, K., 2007. A synopsis of baltic amber termites (Isoptera). Stuttgarter Beiträge zur Naturkunde, Serie B 372, 1-20.

Engel, M.S., Grimaldi, D.A., Krishna, K., 2009. Termites (Isoptera): Their Phylogeny, Classification, and Rise to Ecological Dominance. American Museum Novitates,

1-27.

Farris, J.S., Källersjö, M., Kluge, A.G., Bult, C., 1995. Testing significance of incongruence. Cladistics 10, 315-319.

Fougeyrollas, R., Dolejsova, K., Sillam-Dusses, D., Roy, V., Poteaux, C., Hanus, R. Rosin, Y., 2015. Asexual queen succession in the higher termite Embiratermes neotenicus. Proc. Roy. Soc. B Biol. Sci. 282.

Gentry, J.B., Whitford, W.G., 1982. The relationship between wood litter infall and relative abundance and feeding activity of subterranean termites Reticulitermes spp. in three southeastern coastal plain habitats. Oecologia 54, 63-67.

Ghesini, S., Marini, M., 2012. Morphology and phylogeny of Reticulitermes sp. (Isoptera, Rhinotermitidae) from Cyprus. Bull. Entomol. Res. 102, 672-681.

Grimsson, F., Denk, T., 2005. Fagus from the Miocene of Iceland: systematics and biogeographical considerations. Rev. Palaeobot. Palynol. 134, 27-54.

Grismer, L.L., Ota, H., Tanaka, S., 1994. Phylogeny, classification and biogeography of Goniurosaurus kuroiwae (Squamata: Eublepharidae) from the Ryukyu Archipelago, Japan, with description of a new subspecies. Zoolog. Sci. 11, 319-335.

Haponski, A.E., Stepien, C.A., 2013. Phylogenetic and biogeographical relationships of the Sander pikeperches (Percidae: Perciformes): patterns across North America and Eurasia. Biol. J. Linn. Soc. 110, 156-179.

Hay, W.W., DeConto, R., Wold, C.N., Wilson, K.M., Voigt, S., Schulz, M., Wold-Rossby, A., Dullo, W.-C., Ronov, A.B., Balukhovsky, A.N., Soeding E., 1999. Alternative global cretaceous paleogeography. In: Barrera, E., Johnson, C. (Ed.), The Evolution of Cretaceous Ocean/Climate Systems, Geological Society of America Special Paper 332, pp. 1-47

Honda, M. Kurita, T., Toda, M., Ota, H., 2014. Phylogenetic relationships, genetic divergence, historical biogeography and conservation of an endangered gecko, Goniurosaurus kuroiwae (Squamata: Eublepharidae), from the Central Ryukyus, Japan. Zoolog. Sci. 31, 309-320.

Hongoh, Y, Deevong, P., Inoue, T., Moriya, S., Trakulnaleamsai, S., Ohkuma, M. Vongkaluang, C., Noparatnaraporn, N., Kudo, T., 2005. Intra- and interspecific comparisons of bacterial diversity and community structure support coevolution of gut microbiota and termite host. Appl. Environ. Microbiol. 71, 6590-6599.

Huang, Q.Y., Li, G.H., Husseneder, C., Lei, C.L., 2013. Genetic analysis of population structure and reproductive mode of the termite Reticulitermes chinensis snyder.

PLoS One 8.

Inward, D.J., Vogler, A.P., Eggleton, P., 2007. A comprehensive phylogenetic analysis of termites (Isoptera) illuminates key aspects of their evolutionary biology. Mol Phylogenet. Evol. 44, 953-967.

Jarzembowski, E.A., 1980. Fossil insects from the Bembridge Marls, palaeogene of 293 the Isle of Wight, southern England. Bull. Brit. Mus. Nat. Hist. (Geol.) 33, 237

Jenkins, T.M., Dean, R.E., Verkerk, R., Forschler, B.T., 2001. Phylogenetic analyses of two mitochondrial genes and one nuclear intron region illuminate European subterranean termite (Isoptera: Rhinotermitidae) gene flow, taxonomy, and introduction dynamics. Mol. Phylogenet. Evol. 20, 286-293.

Jolivet, L., Tamaki, K., Fournier, M., 1994. Japan sea, opening history and mechanism: a synthesis. J. Geophys. Res. 99, 22237-22259.

Kambhampati, S., Smith, P.T., 1995. PCR primers for the amplification of four insect mitochondrial gene fragments. Insect Mol. Biol. 4 (4), 233-236.
Kawatsu, K., Matsuura, K., 2013. Preadaptation for parthenogenetic colony foundation in subterranean termites Reticulitermes spp. (Isoptera: Rhinotermitidae). J. Ethol. 31, 123-128.

Ketmaier, V., Giusti, F., Caccone, A., 2006. Molecular phylogeny and historical biogeography of the land snail genus Solatopupa (Pulmonata) in the periTyrrhenian area. Mol. Phylogenet. Evol. 39, 439-451.

Kim, M.J., Choi, Y.S., Lee, J., Kim, J.J., Kim, G.H., 2012. Molecular characteristics of subterranean termites of the genus Reticulitermes (Isoptera: Rhinotermitidae) from Korea. Ann. Entomol. Soc. Am. 105, 97-102.

Kizaki, K., 1986. Geology and tectonics of the Ryukyu Islands. Tectonophysics 125 , 193-207.

Kobayashi, K., Hasegawa, E., Yamamoto, Y., Kawatsu, K., Vargo, E.L., Yoshimura, J., Matsuura, K., 2013. Sex ratio biases in termites provide evidence for kin selection. Nat. Commun. 4.

Krishna, K., Grimaldi, D.A., Krishna, V., Engel, M.S., 2013. Treatise on the Isoptera of the world. Bull. Am. Mus. Nat. Hist. 377, 1-2704.

Kutnik, M., Uva, P., Brinkworth, L., Bagneres, A.G., 2004. Phylogeography of two European Reticulitermes (Isoptera) species: the Iberian refugium. Mol. Ecol. 13, 3099-3113.

Lee, T.R., Cameron, S.L., Evans, T.A., Ho, S.Y., Lo, N., 2015. The origins and radiation of Australian Coptotermes termites: from rainforest to desert dwellers. Mol. Phylogenet. Evol. 82 (Pt. A), 234-244.

Lefebvre, T., Chaline, N., Limousin, D., Dupont, S., Bagneres, A.G., 2008. From speciation to introgressive hybridization: the phylogeographic structure of an island subspecies of termite, Reticulitermes lucifugus corsicus. BMC Evol. Biol. 8

Leniaud, L. Dedeine, F., Pichon, A., Dupont, S., Bagneres, A.G., 2010. Geographica distribution, genetic diversity and social organization of a new European termite, Reticulitermes urbis (Isoptera: Rhinotermitidae). Biol. Invasions 12 1389-1402.

Lo, N., Kitade, O., Miura, T., Constantino, R., Matsumoto, T., 2004. Molecular phylogeny of the Rhinotermitidae. Insectes Soc. 51, 365-371.

Luchetti, A., Marini, M., Mantovani, B., 2007. Filling the European gap: biosystematics of the eusocial system Reticulitermes (Isoptera, Rhinotermitidae) in the Balkanic Peninsula and Aegean area. Mol. Phylogenet. Evol. 45, 377-383.

Luchetti, A., Scicchitano, V., Mantovani, B., 2013a. Origin and evolution of the Italian subterranean termite Reticulitermes lucifugus (Blattodea, Termitoidae, Rhinotermitidae). Bull. Entomol. Res. 103, 734-741.

Luchetti, A., Velona, A., Mueller, M., Mantovani, B., 2013b. Breeding systems and reproductive strategies in Italian Reticulitermes colonies (Isoptera: Rhinotermitidae). Insectes Soc. 60, 203-211.

Luchetti, A., Trenta, M., Mantovani, B., Marini, M., 2004. Taxonomy and phylogeny of north mediterranean Reticulitermes termites (Isoptera, Rhinotermitidae): a new insight. Insectes Soc. 51, 117-122.

Maekawa, K., Lo, N., Kitade, O., Miura, T., Matsumoto, T., 1999. Molecular phylogeny and geographic distribution of wood-feeding cockroaches in East Asian islands. Mol. Phylogenet. Evol. 13, 360-376.

Maekawa, K., Matsumoto, T., 2003. Biogeography of Japanese wood-feeding cockroaches genus Salganea and Panesthia (Blaberidae: Panesthiinae). Mol.

Phylogenet. Evol. 27, 156-159.

Marini, M., Mantovani, B., 2002. Molecular relationships among European samples of Reticulitermes (Isoptera, Rhinotermitidae). Mol. Phylogenet. Evol. 22, 454459.

Maruyama, S., Isozaki, Y., Kimura, G., Terabayashi, M., 1997. Paleogeographic maps of the Japanese Islands: plate tectonic synthesis from 750 Ma to the present. sland Arc 6, 121-142.

Matsuura, K., 2011. Sexual and asexual reproduction in termites. In: Bignell, D.E., Roisin, Y., Nathan, L. (Eds.), Biology of Termites: A Modern Synthesis. Springer, pp. 255-277.

Matsuura, K., Vargo, E.L., Kawatsu, K., Labadie, P.E., Nakano, H., Yashiro, T., Tsuji, K., 1687.

Meulenkamp, J.E., 1985. Aspects of the late Cenozoic evolution of the Aegean region. In: Stanley, D.J., Wezel, F.-C. (Eds.), Geological Evolution of the Mediterranean Basin. Springer-Verlag, New York, pp. 307-321.

Meulenkamp, J.E., Sissingh, W., 2003. Tertiary palaeogeography and tectonostratigraphic evolution of the Northern and Southern PeriTethys platforms and the intermediate domains of the African-Eurasian convergent plate boundary zone. Palaeogeogr. Palaeoclimatol. Palaeoecol. 196 209-228.

Meulenkamp, J.E., Sissingh, W., Calvo, J.P., Daams, R., Studencka, B., Londeix, L., Cahuzac, B., Kovac, M., Nagymarosy, A., Rusu, A., Badescu, D., Beniamovskii, V. N., Scheerba, I.G., Roger, J., Platel, J.-P., Hirsh, F., Sadek, A., Abdel-Gawad, G.I., Ben Ismail-Lattrache, K., Zaghbib-Turki, D., Buaziz, S., Karoui-Yaakoub, N., Yaich, C., 2000. Late Lutetian (44-41 Ma). In: Crasquin, S., (Coord.), Atlas Peri-Tethys, Palaeogeographical Maps - Explanatory Notes, CCGM/CGMW, Paris, pp. 163-170.

Miura, T., Roisin, Y., Matsumoto, T., 2000. Molecular phylogeny and biogeography of the nasute termite genus Nasutitermes (Isoptera: Termitidae) in the Pacific

tropics. Mol. Phylogenet. Evol. 17, 1-10.

Miura, T., Scharf, M.E., 2011. Molecular basis underlying caste differentiation in termites. In: Bignell, D.E., Roisin, Y., Nathan, L. (Eds.), Biology of Termites: A Modern Synthesis. Springer, pp. 211-253.

Mukha, D., Wiegmann, B.M., Schal, C., 2002. Evolution and phylogenetic information content of the ribosomal DNA repeat unit in the Blattodea (Insecta). Insect Biochem. Mol. Biol. 32, 951-960. 
Ohkuma, M., Brune, A., 2011. Diversity, structure, and evolution of the termite gut microbial community. In: Bignell, D.E., Roisin, Y., Nathan, L. (Eds.), Biology of Termites: A Modern Synthesis. Springer, pp. 413-438.

Ota, H., 1998. Geographic patterns of endemism and speciation in amphibians and reptiles of the Ryukyu archipelago, Japan, with special reference to their paleogeographical implications. Res. Popul. Ecol. 40, 189-204.

Park, Y.C., Kitade, O., Schwarz, M., Kim, J.P., Kim, W., 2006. Intraspecific molecular phylogeny, genetic variation and phylogeography of Reticulitermes speratus (Isoptera: Rhinotermitidae). Mol. Cells 21, 89-103.

Perdereau, E., Bagneres, A.G., Bankhead-Dronnet, S., Dupont, S., Zimmermann, M., Vargo, E.L., Dedeine, F., 2013. Global genetic analysis reveals the putative native source of the invasive termite, Reticulitermes flavipes, in France. Mol. Ecol. 22, 1105-1119.

Perdereau, E., Bagneres, A.G., Vargo, E.L., Baudouin, G., Xu, Y., Labadie, P., Dupont, S., Dedeine, F., 2015. Relationship between invasion success and colony breeding structure in a subterranean termite. Mol. Ecol. 24, 2125-2142.

Rögl, F., 1999. Mediterranean and Paratethys palaeogeography during the Oligocene and Miocene. In: Agusti, J., Rook, L. (Eds.), The evolution of Neogene Terrestrial Ecosystem in Europe. Cambridge University Press, Cambridge, UK, pp. 8-22.

Roisin, Y., Hanus, R., Fournier, D., 2014. Asexual queen succession in soil-feeding termites Cavitermes tuberosus. The XVII International Congress of IUSSI: \#34, Cairns, Australia.

Ronquist, F., Teslenko, M., van der Mark, P., Ayres, D.L., Darling, A., Hohna, S., Larget, B., Liu, L., Suchard, M.A., Huelsenbeck, J.P., 2012. MrBayes 3.2: efficient Bayesian phylogenetic inference and model choice across a large model space. Syst. Biol. 61, 539-542.

Sanmartin, I., Enghoff, H., Ronquist, F., 2001. Patterns of animal dispersal, vicariance and diversification in the Holarctic. Biol. J. Linn. Soc. 73, 345-390.

Scudder, S.H., 1883. The fossil white ants of Colorado. Proc. Am. Acad. Arts Sci. 19, 133-145.

Simon, C., Frati, F., Beckenbach, A., et al., 1994. Evolution, weighting, and phylogenetic utility of mitochondrial gene-sequences and a compilation of conserved polymerase chain-reaction primers. Ann. Entomol. Soc. Am. 87, 651701.

Smith, S.A., Dunn, C.W., 2008. Phyutility: a phyloinformatics tool for trees, alignments and molecular data. Bioinformatics 24, 715-716.

Snyder, T.E., 1928. A new Reticulitermes from Baltic sea amber (Insecta, Isoptera). J. Wash. Acad. Sci. 18, 515-517.

Stamatakis, A., 2006. RAxML-VI-HPC: maximum likelihood-based phylogenetic analyses with thousands of taxa and mixed models. Bioinformatics 22, 26882690.

Stamatakis, A., Hoover, P., Rougemont, J., 2008. A rapid bootstrap algorithm for the RAxML web servers. Syst. Biol. 57, 758-771.
Stepien, C.A., Behrmann-Godel, J., Bernatchez, L., 2015. Evolutionary relationships, population genetics, and ecological and genomic adaptations of perch (Perca). In: Couture, P., Pyle, G. (Eds.), Biology of Perch. CRC Press, pp. 7-46.

$\mathrm{Su}$, N.Y., 2002. Novel technologies for subterranean termite control. Sociobiology 40 95-101.

Sun, X.J., Wang, P.X., 2005. How old is the Asian monsoon system? Palaeobotanical records from China. Palaeogeogr. Palaeoclimatol. Palaeoecol. 222, 181-222.

Swofford, D.L., 2001. PAUP* - Phylogenetic Analysis Using Parsimony (*and Other Methods), Ver 4b. Sinauer Associates, Sunderland, MA.

Thompson, G.J., Kitade, O., Lo, N., Crozier, R.H., 2000. Phylogenetic evidence for a single, ancestral origin of a 'true' worker caste in termites. J. Evol. Biol. 13, 869881.

Tiffney, B.H., 2008. Phylogeography, fossils, and Northern Hemisphere biogeography: the role of physiological uniformitarianism. Ann. Mo. Bot Gard. 95, 135-143.

Uva, P., Clément, J.L., Austin, J.W., Aubert, J., Zaffagnini, V., Quintana, A., Bagneres, A G., 2004. Origin of a new Reticulitermes termite (Isoptera, Rhinotermitidae) inferred from mitochondrial and nuclear DNA data. Mol. Phylogenet. Evol. 30 344-353.

Vargo, E.L., Husseneder, C., 2009. Biology of subterranean termites: insights from molecular studies of Reticulitermes and Coptotermes. Annu. Rev. Entomol. 54 379-403.

Vargo, E.L., Labadie, P.E., Matsuura, K., 2012. Asexual queen succession in the subterranean termite Reticulitermes virginicus. Proc. Roy. Soc. B Biol. Sci. 279, 813-819.

Velonà, A., Ghesini, S., Luchetti, A., Marini, M., Mantovani, B., 2010. Starting from Crete, a phylogenetic re-analysis of the genus Reticulitermes in the Mediterranean area. Mol. Phylogenet. Evol. 56, 1051-1058.

Wang, P., 2013. Cenozoic deformation and the history of sea-land interactions in Asia. In: Clift, P., Kuhnt, W., Wang, P., Hayes, D. (Eds.), Continent-ocean Interactions within East Asian Marginal Seas. American Geophysical Union, Washington, D.C.. http://dx.doi.org/10.1029/1149GM1001.

Wu, J., Su, X. Kong, M. Liu, M. Xing, L, 2013. Multiple male and female reproductive strategies and the presence of a polyandric mating system in the termite Reticulitermes labralis (Isoptera: Rhinotermitidae). Sociobiology 60 459-465.

Ye, W.M., Lee, C.Y., Scheffrahn, R.H., Aleong, J.M., Su, N.Y., Bennett, G.W., Scharf, M.E. 2004. Phylogenetic relationships of nearctic Reticulitermes species (Isoptera: Rhinotermitidae) with particular reference to Reticulitermes arenincola Goellner. Mol. Phylogenet. Evol. 30, 815-822.

Zachos, J., Pagani, M., Sloan, L., Thomas, E., Billups, K., 2001. Trends, rhythms, and aberrations in global climate 65 Ma to present. Science 292, 686-693. 